\title{
Re-use of public sector information in cultural heritage institutions
}

\author{
Paul Keller, ${ }^{a}$ Thomas Margoni, ${ }^{b}$ Katarzyna Rybicka ${ }^{b c}$ Alek Tarkowskic \\ (a) Kennisland.nl; (b) Institute for Information Law (IViR); \\ (c) Centrum Cyfrowe Projekt: Polska
}

DOI: $\underline{10.5033 / \text { ifosslr.v6i1.104 }}$

\begin{abstract}
In 2013 the European Union amended the Directive on Public Sector Information, establishing the principle that all available information produced and collected by public sector institutions must be made available for reuse under open terms and conditions. The amended Directive also brings publicly funded libraries, museums and archives into its scope. These new rules on reuse of heritage materials, treated as public sector information (PSI), attempt for the first time to define a general framework for sharing cultural heritage information all around Europe. In this paper we argue that if Member States are not careful, the implementation of the changes required by the new Directive could do more harm than good when it comes to access to digitised cultural heritage in Europe. These concerns relate to how the directive interacts with copyright legislation. The paper recommends that in order to contribute to the opening up of cultural heritage resources, Member States should ensure that all qualifying documents that are not currently covered by third party intellectual property rights fall within the scope of the Directive. Member States should also implement the Directive in a way that will not require institutions to charge for the reuse of works that they make available for reuse. For documents that are still protected by intellectual property rights but where these rights are held by the cultural heritage institutions, Member States should encourage the use of Open Definitioncompliant licences.
\end{abstract}

\section{Keywords}

Law; information technology; public sector information; public domain; intellectual property rights; open formats; open licences.

\section{Introduction}

A decade ago, the European Union established rules for the re-use of public sector information in 
Directive 2003/98/EC on the re-use of public sector information (2003 Directive) ${ }^{1}$, which went into effect on 31 December 2003. It was designed to encourage EU Member States to make information and resources that they produce and collect reusable to the greatest possible extent. Re-use rules have been devised as complementary to the citizens' rights of access to public sector information, which remains regulated by national law. However, while such an access is often seen as a basic civil right, re-use is considered an economic right. In fact, beyond fuelling the innovation and creativity that stimulate economic growth, open public sector information also empowers citizens, thereby enhancing participatory democracy and promoting transparent, accountable and more efficient government. From this perspective, public sector information, when re-used, becomes the basis for added economic, civic, and social value, as recognised by the same Commission.

\section{Re-use of cultural heritage resources}

The 2003 Directive included in its scope information held only by some Public Sector Bodies (PSB) such as ministries, states agencies, municipalities and organisations funded for the most part by, or under the control of, public authorities. ${ }^{2}$ It explicitly excluded cultural, scientific and educational institutions and their resources ${ }^{3}$.

In June 2013 the 2003 Directive was amended by Directive 2013/37/EU (2013 Directive) ${ }^{4}$ which placed museums, libraries (including university libraries) and archives within its scope. However, information held by institutions such as orchestras, operas, ballets and theatres were not included in the scope of the amending Directive ${ }^{5}$, and the same holds true for Public Broadcasting Organisations. ${ }^{6}$

While some of the rules for cultural heritage institutions deviate from the general PSI re-use rules, the rationale for including these institutions under the new consolidated PSI Directive is the same: cultural heritage resources are seen as documents on which added value can be built for commercial gain and the public benefit. These new rules on re-use of heritage materials, treated as public sector information, attempt for the first time to define a general framework for sharing cultural heritage information all around Europe ${ }^{7}$.

The 2013 Directive introduces a number of new features, one of which is the important "re-usable by default" rule. This rule provides that all the information already publicly accessible under national laws will also be considered re-usable. ${ }^{8}$

1 Directive 2003/98/EC on the re-use of public sector information

2 The Directive defines documents as "any content whatever its medium (written on paper or stored in electronic form or as a sound, visual or audiovisual recording) and any part thereof"; See Art. 2(3) PSI Directive (consolidated version).

3 See Article 2.1 (f) which states that 'this directive shall not apply to ... documents held by cultural establishments, such as museums, libraries, archives, orchestras, operas, ballets and theatres'.

4 Directive 2013/37/EU amending Directive 2003/98/EC on the re-use of public sector information

5 Article 2.1 (f) of the consolidated directive now states that 'this directive shall not apply to ... documents held by cultural establishments other than libraries, museums and archives'

6 While the scope of cultural institutions covered by the new regulation seems quite clear, doubts arise in the case of institutions that are not explicitly referred to as a libraries, archives or museums, but that accumulate cultural resources. For example, the Polish National Filmotheque is a film archive, but formally not defined as such. Since the scope of the Directive is to increase the availability of heritage collections, it should be interpreted as to include those institutions that despite a different nomen carry out the same function.

7 In addition to the 28 Member States of the EU the directive is also applicable to the member states of the European Economic Area and can be expected to have a strong normative influence on countries that aspire to join the European Union.

8 See Art. 3(1) consolidated version. 
Cultural heritage institutions may take advantage of a specific exception to this general rule and they may choose whether or not to make documents for which they hold intellectual property rights available for re-use. ${ }^{9}$ However, when they choose to do so, documents must be re-usable for commercial or non-commercial purposes in accordance with the conditions established by the consolidated Directive for other documents held by cultural heritage institutions.

Cultural heritage resources are already being shared by cultural heritage institutions in all EU Member States ${ }^{10}$ however, this practice entirely depends on the policies, funds, resources and efforts of a given institution. In this regard, the implementation of the new 2013 Directive is not expected to cause any revolutionary changes. Yet, if implemented correctly, this new Directive can lead to the establishment of Europe-wide standard rules for the availability of cultural resources, and increase the scale at which cultural heritage information is shared. On the other hand, an implementation contrary to the spirit of the Directive could lead to the creation of unnecessary hurdles to the re-use of public sector information, which would frustrate the very principle that inspired both the 2003 and 2013 Directives.

\section{Charging for re-use}

The consolidated Directive establishes a number of conditions that apply to the re-use of documents falling within its scope, such as the principle of non-discrimination and rules related to charging for re-use of documents. In principle, the consolidated Directive limits charging for reuse to cover only "marginal costs" - the costs necessary to make the resources available. However, some public institutions are "required to generate revenue to cover a substantial part of their costs relating to the performance of their public tasks or of the costs relating to the collection, production, reproduction and dissemination of certain documents made available for re-use," and thus are permitted to charge above the marginal cost. ${ }^{11}$

The Directive states that libraries, museums and archives are explicitly allowed to charge above marginal cost, but charges "should not exceed the cost of collection, production, reproduction, dissemination, preservation and rights clearance, together with a reasonable return on investment." In the past, the allowed level of such return on investment has been ambiguous. The EU legislator indicates that "the prices charged by the private sector for the re-use of identical or similar documents could be considered when calculating a reasonable return on investment". This means that the Directive allows cultural institutions to make profit by supplying and allowing re-use of their resources. ${ }^{12}$

9 See Art. 3(2) of the consolidated version.

10 Europeana.eu alone brings together more than 30 million objects from more than 2500 institutions from all 28 Member States.

11 See Art. 6 consolidated version.

12 This is further explained in the recent "Commission notice - Guidelines on recommended standard licences, datasets and charging for the re-use of documents" it is pointed that return on investment can be understood as a percentage allowing for recovery of the cost of capital and inclusion of a real rate of return (profit). Guidelines refer also to comparing prices to commercial players in a comparable market and conclude that since public cultural institutions do not bear the business risk the way the private sector does, a "reasonable" rate of return would be "slightly above the current cost of capital but well below the average rate of return for commercial players, which is likely to be much higher due to the higher level of risk incurred". 


\section{Third party intellectual property rights - limitations of the scope of the Directive}

The Directive limits the type of information that falls within its scope in relation to the existence of intellectual and industrial property rights. A first case of exclusion from the Directive's scope relates to documents for which third parties (meaning not the cultural heritage institution) hold intellectual property rights such as copyright, related or neighbouring rights as well as sui generis forms of protection. ${ }^{13}$ Thus, for works covered by third party intellectual property rights there is no re-use obligation.

A second case of exclusion relates to documents protected by "industrial property rights" defined as patents, registered designs and trademarks. In this case the exclusion is absolute, as it operates irrespective of the right holder. In other words, no obligation to allow re-use applies when a document is covered by an industrial property right --including those cases where the right holder is the library or museum itself.

As a result of these two cases of exclusion, documents held by cultural heritage institutions are within the scope of the consolidated Directive only if: (i) they are in the public domain, either because they were never protected by copyright or because copyright has expired; or (ii) the cultural heritage institution is the original right holder or assignee of the intellectual property rights.

That being said, it is important to note that the reuse obligations deriving from these two situations diverge. For (i) documents that are in the public domain the general rule applies: documents must be re-usable if they are generally accessible (Art. 3(1)). In the different case of (ii) documents for which the institution holds the copyright and/or related rights the derogatory rule of Art. 3(2) applies: the institution can decide whether it wants to allow re-use or not. Nonetheless, if re-use is allowed it must follow the general requirements of transparency and non-discrimination, as well as the specific limits on the charging policy (see below).

Consequently, documents whose intellectual property rights belong to third parties, but a specific copy thereof is held by a cultural heritage institution are excluded from the Directive, as confirmed by Recital 22 and Art. 1(b) of the consolidated version, and accordingly there is no obligation to allow re-use.

Unfortunately, Recital 9 of the 2013 Directive introduces some uncertainty. ${ }^{14}$ It might be interpreted as implying that any document held by a library but originally owned by a third party and whose term of protection has not yet expired is a document for which third parties hold an intellectual property right, and therefore is excluded from the scope of the Directive. This reading seems contrary to the provisions established in Article 3 (consolidated version) and contradicts the overall objectives and principles enshrined in the Directive (to open-up public knowledge for reuse). It would further create an unjustified limit to the re-use of PSI in clear contradiction with the

13 Rights covered include performers' performances, sound recordings/phonograms, broadcasts of broadcasting organisations and first fixations of films, as well as the sui generis database right and other related rights created or allowed by the EU legal framework (such as scientific and critical editions, non original photographs, published editions, typographical arrangements, etc).

14 "Taking into account Union law and the international obligations of Member States and of the Union, particularly under the Berne Convention for the Protection of Literary and Artistic Works and the Agreement on Trade-Related Aspects of Intellectual Property Rights, documents for which third parties hold intellectual property rights should be excluded from the scope of Directive 2003/98/EC. If a third party was the initial owner of the intellectual property rights for a document held by libraries, including university libraries, museums and archives and the term of protection of those rights has not expired, that document should, for the purpose of this Directive, be considered as a document for which third parties hold intellectual property rights". 
legislative history and legal background of the Directive (both versions). ${ }^{15}$

Given this potential for confusion, it is important that Member States implement the 2013 Directive in line with the rules laid down in Article 3(2) (consolidated version). This means that all documents for which the institution holds the relevant intellectual property rights are subject to the discretionary decision to allow re-use. If re-use is granted, then it will be subject to the other conditions established by the consolidated Directive. This also applies to documents that have been acquired by public institutions from third parties, provided that the intellectual property rights have also been transferred to the institution (or other similar agreement to the same effect has been made). ${ }^{16}$ Recital 9 (2013 Directive) should be interpreted as simply meaning that documents are outside the scope of the directive when the cultural heritage institution holds a document for which it does not simultaneously hold the intellectual property rights, including the situation where the right holder is unknown. ${ }^{17}$

\section{Public domain and public sector information}

Overall, the Directive is in line with the current trends in regard to digitisation of cultural resources held by public institutions. Often these digitisation projects focus on works in the public domain and works for which institutions own the relevant intellectual property rights. For both financial and practical reasons, cultural institutions have been mainly digitising out-of-copyright works.

15 Recital 9 speaks of third party rights insisting on documents held (not owned) by university libraries, archives or museums. The reference should be intended to refer to works protected by a copyright owned by a third party, and for which the library or museum has only acquired the physical ownership of a copy, or in any case a mere right to display or lend the document. Cases where the cultural heritage institution does not just hold the document but owns it too and is its copyright holder - should therefore be excluded from the scenario of Recital 9 (2013 Directive).

16 This view seems supported by the legislative history of that provision. Nowhere in the drafts that lead to the 2013 Directive is suggested a reading or interpretation that would significantly derogate from the overall scope of the Directive, i.e. favouring re-use of PSI. In particular, previous versions of current Recital 9 of the 2013 Directive, set forth the principle of "strict necessity" which seems to better explain the real function of said Recital. Recital 7 of the Explanatory Memorandum (which corresponds to current Recital 9 of the 2013 Directive) had an opening text which is reported for the convenience of the reader: "Directive 2003/98/EC should therefore lay down a clear obligation for Member States to make all generally available documents re-usable. As it constitutes a limitation to the intellectual property rights held by the authors of the documents, the scope of such a link between the right of access and the right of use should be narrowed to what is strictly necessary to reach the objectives pursued by its introduction. In this respect, taking into account the Union legislation and Member States' and Union's international obligations, notably under the Berne Convention for the Protection of Literary and Artistic Works and the Agreement on Trade-Related Aspects of Intellectual Property Rights (the TRIPS Agreement), documents on which third parties ...". It must also be noted that any different reading would clearly envisage a contradiction between Recital 9 of the 2013 Directive and Art. 3. Suffice to recall that "the preamble to a Community act has no binding legal force and cannot be relied on as a ground for derogating from the actual provisions of the act in question or for interpreting them in a manner clearly contrary to their wording"; See Case C-162/97 Nilsson and Others [1998], paragraph 54, and Case C-308/97 Manfredi [1998], paragraph 30. The EC seems to have recently adopted a similar view on the relationship between Recital 9 and Art. 3 of the 2003 Directive; see below fn 16.

17 This view seems to be supported by the same European Commission, at least informally. In the Minutes of the $19^{\text {th }}$ Meeting of the Public Sector Information Group, held in Luxembourg on September $10^{\text {th }}, 2014$, the EC expressed the following opinion in response to a specific question on the meaning of Recital 9: "The second sentence of recital 9 appears to suggest that documents whose IPR has been acquired by the cultural institution from third parties should be treated as covered by 3rd party IPR and therefore excluded from the scope of the Directive. In fact, the second sentence stresses that 3rd party IP rights on documents held by cultural institutions should be respected even in cases where identifying the right holder is difficult (circumstances in which such works can be used are normally covered by Directive 2012/28/EU - the Orphan Works Directive). The Commission is of an opinion that recitals cannot undo the operational provisions in the body of a Directive and in this case the application based on the literal reading of article 3 seems the best way to ensure the objectives of the PSI Directive. Therefore, the second sentence of recital 9 should rather be interpreted as encompassing only those situations in which cultural institutions physically own copies of documents, which are still protected by copyright but the right holders of which are unknown (orphan works)". Orphan works are therefore excluded from the general re-use rule. Orphan works are now object of the specific provisions contained in Directive 2012/28/EC on certain permitted uses of orphan works". The Minutes are available at http://ec.europa.eu/digital-agenda/en/news/public-sector-information-group-main-page. 
While the Directive will not change this situation, it could produce a negative effect on the availability of public domain works to the general public.

The current best practice with regard to digitisation of public domain materials by cultural heritage institutions is to make these materials available for free and without restrictions on re-use ${ }^{18}$. The digitisation of public domain works has been an important driver for the nascent open data movement in the cultural heritage sector.

From a policy perspective, cultural heritage institutions that decide to make public domain works available under conditions that limit or regulate their re-use could potentially frustrate the inner balance between public and private interests supposedly created by copyright law. Again, the Directive does not, and should not, modify this inner balance of copyright law. Yet, a superficial extension of the 2013 Directive to works held by cultural heritage institutions would produce the unwanted effect of introducing new barriers - mainly financial. Charging will affect the re-use of public domain works and consequently damage the balance established by the temporal nature of copyright.

As outlined above, the Directive (consolidated version) provides cultural heritage institutions with the ability to charge for works that they make available for re-use. While this may be a useful strategy for some institutions to recover a portion of their costs, there are many cases where charging for re-use will limit access to and re-use of the resources in question. ${ }^{19}$ The most appropriate decision can only be made by the CHIs on a case by case basis.

\section{No charging requirements}

National legislatures implementing the 2013 Directive should be careful not to require institutions to charge for the re-use of works that they make publicly available ${ }^{20}$. Adding charging requirements (or encouraging them) could undermine the public domain, limit online access to, and re-use of, cultural heritage resources, and damage the nascent open culture data ecosystem. ${ }^{21}$ The decision whether to charge for re-use should be left with the CHIs which are usually best placed to assess the specific needs on a case by case basis.

When applied to cultural heritage resources that have entered into the public domain such requirements would have the effect of prolonging the access limitation created by the duration of copyright protection - a duration already considered to be too long by many stakeholders. These charging requirements, if implemented improperly, have the potential to undermine the overall objective of the Directive (increasing re-use of resources held by public institutions).

\section{Licensing}

The recitals of the 2013 Directive and a recently published "Guidelines on recommended standard

18 See Europeana's Public Domain Charter or the image re-use policy of the Rijksmuseum.

19 See for example the 'Yellow Milkmaid' white paper published by Europeana in 2011 or the above mentioned image reuse policy of the Rijksmuseum.

20 An existing example of Public Sector Information legislation that encourages institutions to charge for re-use of public domain works that they make available is the French law on access and reuse of public sector information, which has the effect that public domain works available via portals like Gallica cannot be used for commercial purposes without obtaining a license.

21 It should be noted that the Directive defines maximum level of charges and that the first implementations of the amended Directive into national laws often define lower limits. 
licences, datasets and charging for re-use of documents" put a lot of emphasis on the use of standard open licences. Open licences, such as the Creative Commons licences, build on copyright and as a result their attachment to works that are out of copyright should not produce any effects. Accordingly, open licences are not usually enforceable when applied to material that is in the public domain. Clearly, the arguments in favour of standard licences apply equally to standard tools for marking public domain works, such as the Public Domain Mark ${ }^{22}$ and the CC0 Public Domain Dedication. ${ }^{23}$

Open licences (especially those that comply with the Open Definition ${ }^{24}$ ) should be used not only when making available documents but also meta-data for which the copyright lies with the cultural heritage institution - at least in the limited cases where meta-data attract copyright protection (such as original descriptions of cultural heritage objects). ${ }^{25}$

\section{Non-discrimination}

The Directive (consolidated version) requires that all conditions attached to the re-use of documents shall be non-discriminatory for comparable categories of re-use and that the re-use shall be open to all potential actors in the market. To fully realise the potential of open data and to stimulate the development of new services, re-use should be open to all on equal footing. This means that institutions cannot grant access to certain categories of users but refuse it to others, or enter into exclusive agreements with selected partners. However, the Directive contains one important exception that allows exclusive contracts for cultural heritage institutions engaging in digitisation projects. The Directive specifies that such agreements should be limited in time and as short as possible, with a maximum duration of 10 years. ${ }^{26}$

\section{Recommendations for Implementation by Member States}

As we have explained above, the ongoing implementation process in the Member States poses a number of potential pitfalls. If Member States are not careful, the implementation of the 2013 Directive could do more harm than good to the availability of cultural resources held by Europe's cultural heritage institutions. Such an effect would frustrate the intentions expressed by the EC when the 2013 Directive was approved. ${ }^{27}$

22 Public Domain Mark

23 CC0 Public Domain Dedication. According to the Commission's Guidelines, "open standard licences, for example the most recent Creative Commons (CC) licences (version 4.0), could allow the re-use of PSI without the need to develop and update custom-made licences at national or sub-national level. Of these, the CC0 Public Domain Dedication is of particular interest. As a legal tool that allows waiving copyright and database rights on PSI, it ensures full flexibility for re-users and reduces the complications associated with handling numerous licences, with possibly conflicting provisions."

24 Open Definition

25 Meta-data usually represent factual information such as titles, names, and dates. The standard for copyrightability in the entire European Union for any category of works is the "author's own intellectual creation" which is present when the author makes free and creative choices and puts his or her personal stamp in the work. When an output is constrained by technical and factual rules, there is little to no space for free and creative choices, reducing the possibility of protected works only to those meta-data that can show personal, free and creative choices. See also Dr. Till Kreutzer,'Validity of the Creative Commons Zero 1.0 Universal Public Domain Dedication and its usability for bibliographic meta-data from the perspective of German Copyright Law', (2011) for a discussion about the protectability of meta-data published by cultural heritage institutions.

26 There is however an exception to this rule: "In the case when the period exceeds 10 years, its duration shall be subject to review during the 11 th year and, if applicable, every seven years thereafter." which theoretically allows for exclusive contracts with an indefinite duration.

27 E.g. "[The Directive] encourages the Member States to make as much information available for re-use as possible" or "[it] introduces a genuine right to reuse by making reusable all content that can be accessed under national access to 
Accordingly, Member States implementing the 2013 Directive are invited to pay utmost attention to the following three main recommendations:

1. Member States should implement the 2013 Directive in line with the principles established by Article 3 (consolidated version) and ensure that all qualifying documents that are not currently covered by third party intellectual property rights fall within the scope of PSI national legislation.

2. Member States must not implement the Directive in such a way that encourages or requires institutions to charge for works that they make available for re-use. The decision to charge for re-use should be up to the individual institution. If this is not the case, the implementation of the 2013 Directive will limit access to and re-use of the public domain.

3. For documents that are still protected by intellectual property rights, but where these rights are held by the cultural heritage institutions that have these works in their collections, Member States should encourage the use of Open Definition-compliant licences, such as the Creative Commons licences or the Creative Commons Zero mechanism. This applies in particular to meta-data produced by cultural heritage institutions, in the limited cases where these meta-data attract copyright protection.

\section{About the authors}

Paul Keller is Co-Director and Senior Copyright Adviser at Kennisland, Amsterdam.

Thomas Margoni is a Senior Researcher at the Institute for Information Law (IViR), University of Amsterdam.

Katarzyna Rybicka is Policy Analyst at Centrum Cyfrowe Projekt: Polska.

Alek Tarkowski is Director and Head of Policy at Centrum Cyfrowe Projekt: Polska.

documents laws"; see http://ec.europa.eu/digital-agenda/en/european-legislation-reuse-public-sector-information. 


\section{Licence and Attribution}

This paper was published in the International Free and Open Source Software Law Review, Volume 6, Issue 1 (2014). It originally appeared online at http://www.ifosslr.org.

This article should be cited as follows:

Paul Keller, Thomas Margoni, Katarzyna Rybicka,

Alek Tarkowski (2014) 'Re-use of public sector information in cultural heritage institutions', International Free and Open Source Software Law Review, 6(I), pp 1 - 9 DOI: 10.5033/ifosslr.v6i1.104

Copyright (C 2014 Paul Keller, Thomas Margoni, Katarzyna Rybicka, Alek Tarkowski

This article is licensed under the Creative Commons 4.0 attribution licence, CC-BY available at

http://creativecommons.org/licenses/by/4.0

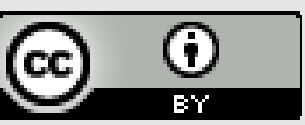


